\title{
Um Estudo sobre a Evasão no Curso de Licenciatura em Informática do IFRN - Campus Natal - Zona Norte
}

\author{
Odair S. Souza, Pauleany S. Morais, Francisco C. Silva Júnior \\ Campus Natal - Zona Norte - Instituto Federal de Educação, Ciência e Tecnologia do \\ Rio Grande do Norte (IFRN), Rua Brusque, 2926, Conjunto Santa Catarina, Potengi \\ CEP 59112-490 - Natal - RN - Brasil \\ odairsds@gmail.com, pauleany.moraiseifrn.edu.br, \\ francisco.juniordifrn.edu.br
}

\begin{abstract}
This paper presents a study on the dropout in the Degree Course in Informatics of IFRN - Campus Natal - North Zone. Based on the analysis of dropout characteristics in the degree courses offered in public higher education institutions, a questionnaire was designed and made available in a website developed exclusively for this project, in order to know the profile of the dropouts students and the reasons why students dropout. The results confirm what other studies have already been presented: the dropout is related to a large number of factors, as the wrong choice of course and the difficulty in reconciling work and study, among others.
\end{abstract}

Resumo. Este artigo apresenta um estudo sobre a evasão no Curso de Licenciatura em Informática do IFRN - Campus Natal - Zona Norte. A partir da análise das características da evasão nos cursos de licenciatura oferecidos nas Instituições de Ensino Superior (IES) públicas, um questionário foi elaborado e disponibilizado em um website desenvolvido exclusivamente para esta pesquisa, com o objetivo de conhecer o perfil dos alunos desistentes e as razões que os levaram a abandonar o curso. Os resultados confirmam o que outros estudos já apresentaram: a evasão está relacionada a uma grande variedade de fatores, como a escolha equivocada do curso e a dificuldade em conciliar trabalho e estudos, dentre outros.

\section{Introdução}

A evasão escolar é um tema que costuma estar na pauta de discussões relacionadas aos problemas da educação em todos os níveis e modalidades de ensino. Porém, sabe-se que no ensino superior a evasão é um fenômeno bem mais complexo. Quando o aluno abandona seus estudos, isso "representa uma perda social, de recursos e de tempo para todos os envolvidos no processo de ensino" [Lobo 2012, p. 1]. Para se ter uma ideia, $41 \%$ dos alunos que cursam alguma licenciatura não chegam a se formar e a cada ano 16,5\% desistem, de acordo com os dados apresentados em [Anibal 2013]. Apesar disso, são raros os casos de instituições de ensino superior (IES) que possuem um programa institucional profissionalizado de combate à evasão [Silva Filho et al. 2007].

No caso dos cursos de licenciatura, foco da discussão apresentada neste artigo, a situação é bastante grave. O desprestígio da profissão, os baixos salários e as más condições de trabalho são fatores determinantes que incentivam a "fuga" em massa dos cursos. O texto apresentado em [Anibal 2013] destaca que as universidades têm se mexido para amenizar o problema, por meio da adesão a programas de incentivo à 
permanência na licenciatura. Uma dessas alternativas é o Programa Institucional de Bolsa de Iniciação à Docência (PIBID), lançado em 2009 pelo Governo Federal. Apesar disso, ainda há muito a ser feito. São problemas e números que se repetem há décadas e, no entanto, as discussões sobre o assunto parecem estar longe do fim.

Sendo assim, a pesquisa apresentada neste artigo, que foi apresentada como trabalho de conclusão de curso [Souza 2014], procura não só compreender de maneira mais detalhada a evasão do Curso de Licenciatura em Informática do Campus Natal Zona Norte do IFRN, mas também apresentar reflexões e contribuições sobre um tema tão preocupante e recorrente em cursos de licenciatura. Uma pesquisa com esse enfoque é o ponto de partida no planejamento de ações para a implantação de melhorias dos serviços oferecidos aos estudantes e, consequentemente, diminuição dos índices de evasão. Como objetivos específicos, esta pesquisa pretende trazer reflexões que contribuam para compreender as dificuldades encontradas pelos estudantes dentro e fora do IFRN para permanecer no curso; conhecer o perfil dos alunos em relação ao curso de licenciatura e ao ensino superior; descobrir quais são os principais motivos que conduziram os mesmos à evasão; e, por fim, apresentar algumas sugestões que possam ser colocadas em prática para melhorar o índice de conclusão no respectivo curso. Mesmo com metodologias um pouco diferentes da que é apresentada neste artigo, outros estudos importantes já foram realizados em instituições como a UFMT [Prietch e Pazeto 2009] e o IFTO [Silva e Bezerra Junior 2014], e servem como referências para o estudo da evasão no curso de Licenciatura em Informática/Computação, de uma forma geral.

Metodologicamente, quanto aos seus objetivos, a pesquisa adota de forma predominante a pesquisa explicativa, entendida como aquela que "preocupa-se em identificar os fatores que determinam ou que contribuem para a ocorrência dos fenômenos" [Gerhardt e Silveira 2009, p. 35], como é o caso da evasão no Curso de Licenciatura em Informática do IFRN. Para a coleta de dados, desenvolveu-se um website específico, em que se encontrava disponibilizado um questionário. Decidiu-se por esta metodologia, já que se trata de um trabalho de conclusão e assim o autor poderia colocar em prática os conhecimentos adquiridos ao longo do curso, além da flexibilidade em se tabular os dados coletados. Com base nos dados fornecidos pela Secretaria Acadêmica do Campus Natal - Zona Norte, o número total de alunos evadidos durante o período considerado para a análise da evasão foi de 135. Entretanto, só foi possível entrar em contato com 102, através de telefone e redes sociais, devido ao fato de algumas informações serem insuficientes ou estarem desatualizadas no cadastro dos alunos. Do total de alunos procurados para participar da pesquisa, 42 responderam ao questionário disponibilizado por meio do website.

É importante ressaltar que os problemas socioeconômicos, psicológicos, familiares, culturais, assim como as redes de relações, organizações estruturais e curriculares, ações metodológicas e pedagógicas, dentre outros, são elementos que influenciam a trajetória do acadêmico no seio universitário. Portanto, diante dos inúmeros fatores possíveis, surgem dificuldades para eleger qual especificamente deve ser estudado e pesquisado. Portanto, optou-se por um estudo diagnóstico que pode apontar indícios de quais direções futuras podem ser adotadas. 


\section{O Curso de Licenciatura em Informática do IFRN}

O Curso Superior de Licenciatura em Informática na modalidade presencial do IFRN possui uma carga horária de 3.404 horas com duração de 4 anos. De acordo com o seu Projeto Pedagógico, o curso promove uma formação comprometida com os valores sociais democráticos, com a compreensão da educação como prática social, com o domínio dos conhecimentos específicos, os conhecimentos pedagógicos e os saberes da experiência [IFRN 2012]. O profissional formado deve ter o perfil para atuar não só na pesquisa na área de computação, mas também na análise de problemas educacionais e também no desenvolvimento de ferramentas computacionais para o apoio aos processos educacionais e de administração escolar, conforme consta no currículo de referência para cursos de Licenciatura em Computação da Sociedade Brasileira de Computação (SBC).

A criação e abertura do curso de Licenciatura em Informática abre espaço para discussão a respeito da reformulação das matrizes curriculares das escolas de educação básica, com a inclusão da disciplina de Informática, visando a elevação do padrão de escolaridade da população brasileira, a expansão do ensino superior, bem como o fortalecimento das políticas estaduais em relação à área de Informática, enquanto ferramenta de promoção do exercício da cidadania.

\section{Números da Evasão na Licenciatura em Informática do IFRN}

Da abertura do Curso de Licenciatura em Informática no Campus Natal - Zona Norte (primeiro semestre letivo de 2010) até o segundo semestre letivo de 2013, o número total de matrículas (MtC) foi de 242. A Tabela 1 mostra a situação dos alunos que deixaram o curso, a partir dos dados obtidos com a Secretaria Acadêmica do campus.

Tabela 1. Números da evasão na Licenciatura em Informática do IFRN.

\begin{tabular}{lc}
\hline Situações & $\mathbf{N}^{\mathbf{0}}$ \\
\hline Evasões (Ev) & 74 \\
\hline Matrículas canceladas (MC) & 57 \\
\hline Jubilados (J) & 11 \\
\hline Transferidos entre turmas (TT) & 10 \\
\hline Transferidos entre cursos (TC) & 4 \\
\hline TOTAL & 156 \\
\hline
\end{tabular}

O número total de evasões no curso (EvTC) no período considerado foi de 135 $(\mathrm{EvTC}=\mathrm{TC}+\mathrm{MC}+\mathrm{Ev})$. Com a razão entre o número de evasão total do curso (EvTC) e matrículas totais no curso (MtC), obtido com a soma de todas as matrículas efetuadas no início de cada turma no período compreendido entre 2010 e 2013, pode-se chegar à Taxa de Evasão do Curso (TEvC) que alcançou 55,78\%, comprovando a grande diminuição do número de alunos desde o seu início e justificando a pesquisa apresentada neste artigo.

\section{Perfil dos Alunos Evadidos e seus Motivos para a Evasão}

Esta seção trata da pesquisa realizada com alunos que se evadiram do Curso de Licenciatura em Informática do IFRN Campus Natal - Zona Norte até o final de 2013, 
com o intuito de compreender os principais motivos da evasão sob a perspectiva da visão dos próprios alunos.

Em sua primeira parte, o questionário apresentava perguntas para a caracterização socioeconômica e cultural do aluno, como tipo de residência, renda familiar, profissão e meio de transporte que o mesmo utilizava para se deslocar até o campus do IFRN. Depois, era perguntado ao aluno a opinião dele sobre seu nível de conhecimento em Informática, a importância de uma formação superior em sua vida, se o mesmo já havia sido aluno do IFRN e sua opinião sobre o curso, indagando-o a respeito do grau de satisfação, da metodologia, dos motivos que o impediram de concluí-lo e se o mesmo pretende voltar, entre outros, por meio de questões de múltipla escolha. Por fim, o questionário continha uma questão livre, com a possibilidade de o aluno expressar sua opinião em relação ao curso por meio de uma resposta do tipo discursiva. A Tabela 2 mostra as respostas mais apresentadas em cada uma das questões que tratavam do perfil social e acadêmico dos estudantes desistentes.

Tabela 2. Principais respostas escolhidas.

\begin{tabular}{ll}
\hline Pergunta & Resposta mais escolhida \\
\hline Tipo de moradia & Casa Própria (78\%) \\
\hline Área de residência & Zona urbana (93\%) \\
\hline Posição familiar & Responsável pela residência (52\%) \\
\hline Trabalhava durante o curso & Sim (71\%) \\
\hline Nível de conhecimento em Informática & Intermediário (52\%) \\
\hline Renda familiar & Três salários mínimos (41\%) \\
\hline Meio de transporte até o campus & Transporte coletivo (62\%) \\
\hline Tipos de benefícios com programas de assistência estudantil & Nenhum (91\%) \\
\hline Estado civil & Solteiro (52\%) \\
\hline Origem estudantil & Escola pública urbana (72\%) \\
\hline Conclusão do Ensino Médio & Há mais de cinco anos (83\%) \\
\hline Importância de Curso Superior & Extremamente importante (64\%) \\
\hline Relação com o Ensino Superior & Nunca cursaram outro curso (43\%) \\
\hline Já foi aluno do IFRN & Sim (62\%) \\
\hline Fazia outro curso em paralelo & Não (69\%) \\
\hline Pretende seguir carreira docente & Sim (38\%) \\
\hline Pretende voltar ao IFRN & Sim, fazendo outro curso (54\%) \\
\hline As condições do campus atendem às expectativas & Concorda parcialmente (47\%) \\
\hline O curso atende ao que o aluno esperava & Concorda parcialmente (50\%) \\
\hline O que faz atualmente & Estuda e trabalha (43\%) \\
\hline
\end{tabular}

Quanto aos objetivos dos alunos quando ingressaram no curso, onde eles poderiam indicar mais de um, $42 \%$ respondeu que fazia o curso superior para se qualificar para o mercado de trabalho, 30\% respondeu que pretendia aprimorar os conhecimentos em Informática, $6 \%$ respondeu que já dava aulas e por isso queria um diploma de licenciado, $18 \%$ respondeu que queria dar continuidade aos estudos e $4 \%$ escolheu como resposta "Outros". Levando-se em conta essas respostas e a condição socioeconômica revelada no questionário, pode-se deduzir que parte considerável desses alunos é caracterizada por trabalhadores que estão em busca de ascensão profissional e enxergavam no curso uma oportunidade de alcançar essa ascensão. 
Porém, segundo esclarece Gomes (2000), sabe-se que quando esses alunos têm suas expectativas frustradas, tendem a abandonar o curso partindo para uma nova opção.

Na Tabela 3 são apresentados os dados referentes aos motivos que levaram os alunos a abandonarem o curso. Esta pergunta permitia aos alunos escolherem mais de uma resposta. Como pode ser observado, a dificuldade para conciliar trabalho e estudos foi uma resposta indicada por $45,24 \%$ do total de alunos, sendo assim a alternativa mais utilizada pelos mesmos para explicar a desistência. Em segundo lugar, com 35,71\% do total, ficou a alternativa que indica que a Licenciatura em Informática não era o curso que eles desejavam. Em terceiro, escolhida por 30,95\% dos alunos, ficou a alternativa que indica que eles foram contemplados com uma bolsa de estudos e/ou passaram no exame de seleção para outro curso.

Tabela 3. Motivos da desistência do curso.

\begin{tabular}{clcr}
\hline $\mathbf{N}^{\mathbf{0}}$ & \multicolumn{1}{c}{ Motivo da saída } & Alunos & $\mathbf{\%}$ \\
\hline 1 & Dificuldade para conciliar trabalho e estudo & 19 & 45.24 \\
\hline 2 & Não era o curso que eu queria & 15 & 35.71 \\
\hline 3 & Fui contemplado com uma bolsa/passei no exame de seleção para outro curso & 13 & 30.95 \\
\hline 4 & Não consegui acompanhar o conteúdo da disciplina de Algoritmos (ou de outras) & 11 & 26.19 \\
\hline 5 & Outros & 11 & 26.19 \\
\hline 6 & Incompatibilidade de horários & 8 & 19.05 \\
\hline 7 & Problemas com professores (métodos de ensino, métodos de avaliação, & 8 & 19.05 \\
& dificuldades de relacionamento) & 5 & 11.90 \\
\hline 8 & Discordo da forma como as coisas são resolvidas na instituição & 5 & 11.90 \\
\hline 9 & Não havia a oportunidade de conseguir um bom emprego após terminar o curso & 4 & 9.52 \\
\hline 10 & Dificuldades econômicas & 4 & 9.52 \\
\hline 11 & Mudança de endereço & 3 & 7.14 \\
\hline 12 & Dificuldade de adaptação ao novo ambiente & 3 & 7.14 \\
\hline 13 & Expectativas frustradas pelas diferenças entre o ensino médio e superior & 2 & 4.76 \\
\hline 14 & Pressões sofridas por parte da família & 1 & 2.38 \\
\hline 15 & Devido à falta de estrutura da instituição & 5
\end{tabular}

Alguns dos motivos importantes indicados pelos alunos no espaço para respostas discursivas foram: a dificuldade com o conteúdo da disciplina de Matemática, o sistema de módulos que na opinião dos mesmos, dificulta o trancamento de disciplinas, o fato de possuir matrícula em IES pública, expectativas frustradas em relação aos objetivos do curso, o fato de ter parado para dar suporte aos estudos de filho(s) e também a falta de segurança nas imediações do campus, o que pode ser comprovado por meio do texto utilizado por uma aluna:

Fui assaltada na esquina da IFRN, fiquei traumatizada e não fui mais, pois compraram nos meus cartões. Até hoje negocio a dívida mas eles não aceitam. Fui prejudicada fisicamente, financeiramente e psicologicamente, ali é perigoso e escuro (espero que a situação tenha mudado) [ALUNA A, 2014]

Outro fator indicado por um dos alunos como motivo - neste caso, decisivo para a desistência do curso está relacionado com as duas greves dos professores do IFRN, ocorridas em 2011 (do dia 18 de agosto ao dia 28 de outubro) e em 2012 (de 21 de junho a 19 de setembro), como pode ser comprovado na justificativa a seguir: 
Com as greves, o calendário de aulas da instituição sofreu modificações, tendo aulas em períodos de recesso das outras universidades. Este fato foi crucial para a minha desistência, visto que eu, morador de uma cidade do interior que diariamente se deslocava mais de $100 \mathrm{~km}$ de casa para a instituição [...] [ALUNO B, 2014]

Com a proximidade entre os períodos dessas duas greves, o calendário acadêmico ficou bastante atrasado, o que sem dúvida, deixou vários alunos descontentes e pode ter influenciado outras desistências como essa.

A Tabela 4 apresenta os dados relativos aos motivos considerados decisivos, dentre os indicados pelos alunos para a desistência do curso. Para esta pergunta, o aluno só podia escolher uma única resposta. Neste caso, o fato de ter sido contemplado com uma bolsa e/ou passar em exame de seleção para outro curso foi a alternativa mais indicada como fator decisivo para a saída do curso. Em segundo lugar, três respostas ficaram empatadas com 5 alunos cada: a dificuldade para conciliar trabalho e estudos, o fato de não ser o curso que eles queriam e o fato de não conseguirem acompanhar o conteúdo da disciplina de Algoritmos (ou de outras).

Com base na elevada ocorrência da terceira alternativa da Tabela 3 , que na Tabela 4 assumiu a primeira posição, pode-se deduzir que uma parte considerável dos alunos optou por tentar cursar dois cursos superiores, sendo o Curso de Licenciatura em Informática do IFRN um deles e mostrando que eles ainda não estavam decididos sobre o que cursar. Porém, à medida que as circunstâncias e suas próprias condições os impediam de se manter nesta situação, optaram por permanecer em apenas um.

Tabela 4. Motivos decisivos para a desistência do curso.

\begin{tabular}{clcc}
\hline $\mathbf{N}^{\mathbf{0}}$ & \multicolumn{1}{c}{ Fator decisivo } & Alunos & $\%$ \\
\hline 1 & Fui contemplado com uma bolsa/passei no exame de seleção para outro curso & 12 & 28.57 \\
\hline 2 & Dificuldade para conciliar trabalho e estudo & 5 & 11.90 \\
\hline 3 & Não consegui acompanhar o conteúdo da disciplina de Algoritmos (ou de outras) & 5 & 11.90 \\
\hline 4 & Não era o curso que eu queria & 5 & 11.90 \\
\hline 5 & Incompatibilidade de horários & 3 & 7.14 \\
\hline 6 & Mudança de endereço & 2 & 4.76 \\
\hline 7 & Problemas com professores (métodos de ensino, métodos de avaliação, & 2 & 4.76 \\
& dificuldades de relacionamento) & 1 & 2.38 \\
\hline 8 & Dificuldades econômicas & 1 & 2.38 \\
\hline 9 & Não havia a oportunidade de conseguir um bom emprego após terminar o curso & 2 &
\end{tabular}

Com relação ao terceiro motivo indicado pelos alunos como fator decisivo para desistência do curso, sabe-se que nos últimos anos o país tem vivenciado um significativo processo de inclusão no ensino superior impulsionado pelo ENEM e pelo Programa Universidade para Todos (PROUNI). Embora Oliveira et al (2014) considere este processo questionável, levando-se "em consideração o cenário de construção da chamada sociedade do conhecimento e, ainda, as mudanças do mundo do trabalho, o processo de mundialização do capital e as alterações que vêm ocorrendo no papel do Estado desde os anos de 1980". O fato é que o mesmo tem proporcionado para muitos estudantes, inclusive para os alunos do Curso de Licenciatura em Informática do IFRN, a tão sonhada oportunidade de entrar em um curso superior. No entanto, de acordo com Rocha, Nicoletti e Hipólito (2013, p. 159), os alunos chegam ao ensino superior com 
uma enorme defasagem na sua trajetória escolar, com uma formação básica cada vez mais deficitária e desconhecem muitos dos conceitos básicos de Matemática, que são pré-requisitos para as disciplinas específicas de cursos relacionados com a área da Computação. Isso se torna um empecilho para um desempenho satisfatório, como é o que acontece no Curso de Licenciatura em Informática do IFRN e é revelado pelos resultados desta pesquisa.

Outro fator importante (que não foi abordado na pesquisa, mas é algo que se comenta frequentemente entre os alunos, conforme foi verificado por um dos autores) e que certamente influenciou a decisão de alguns, portanto, é o fato de que, diferentemente do que acontece em outras licenciaturas, ainda não existe a disciplina de Informática na grade curricular do Ensino Médio no estado do Rio Grande do Norte, o que ocorre também no Ensino Fundamental na cidade de Natal, capital do estado. Dessa forma, não havendo praticamente qualquer demanda pelo professor de Informática. Obviamente, os alunos podem se sentir desmotivados a concluírem um curso de uma área que historicamente apresenta dificuldades e complexidade em suas disciplinas, e isso possivelmente se torna mais um impulsionador da evasão no curso em questão.

Logo, após a observação dos dados, se é levado a acreditar que o fenômeno da evasão vivenciado no Curso de Licenciatura em Informática do IFRN não pode ser interpretado unicamente como exclusão escolar, que é definida por Bueno (1993 apud Brasil (1996), p. 25) como "a admissão de uma responsabilidade da escola e de tudo que a cerca, por não ter mecanismos de aproveitamento e direcionamento do jovem que se apresenta para uma formação profissionalizante", que é uma visão semelhante a que é apresentada em [Medeiros 2002]. Para Bueno (1993 apud Brasil (1996), p. 25), o termo evasão diferencia-se de "exclusão", pois está mais relacionado a "uma postura ativa do aluno que decide desligar-se por sua própria responsabilidade". Porém, é preocupante saber que em alguns casos, mesmo com esforços para se manterem matriculados e seguirem até a conclusão do curso, alguns alunos infelizmente têm que interromper seus sonhos e ir em busca de outras alternativas, seja por motivos financeiros, acadêmicos, ou relativos a transporte e segurança. Pois tais questões, seja direta ou indiretamente, estão relacionadas com a forma como a instituição enfrenta o problema da evasão.

Também pelos mesmos motivos, não se trata pura e simplesmente de evasão da forma como identificaram Machado e Moreira (2010) ou de "mobilidade" como esclarece Ristoff (1995 apud Brasil (1996), p. 25), entendida como "a tentativa de buscar o sucesso ou felicidade aproveitando as revelações que o processo natural dos indivíduos faz sobre suas reais potencialidades". Mas vale lembrar que em alguns casos, mesmo com a boa avaliação que os alunos fizeram em relação ao campus e ao curso, os mesmos optaram pela saída, priorizando a matrícula em outra instituição ou em outro curso mais relacionado com a sua área de interesse, ou ainda com maior probabilidade de ascensão profissional.

\section{Possibilidades de Reflexão e Combate à Evasão}

Percebe-se nas seções anteriores deste artigo a necessidade de se colocar em prática algumas ações que tenham como enfoque amenizar os índices elevados de evasão. Nesse sentido, para apoiar os alunos com dificuldade relacionada aos conteúdos de disciplinas com altas taxas de reprovação, pode ser elaborado, por exemplo, um projeto em que os alunos que estão na etapa final do curso, e têm familiaridade com essas disciplinas, apoiem os alunos que estão no início do curso, tirando suas dúvidas e 
orientando-os na resolução de problemas, além de trocar experiências, dando a oportunidade de ampliação e renovação dos conhecimentos para os que estão saindo e tranquilidade para os que estão entrando.

Para combater o problema da falta de informação em relação ao curso, podem ser realizadas palestras e também ampla divulgação através de material impresso ou redes sociais para estudantes do Ensino Médio em escolas públicas das proximidades do campus.

Em relação aos motivos socioeconômicos da evasão, ampliar o número de vagas nos programas de assistência estudantil pode diminuir o número de alunos que se evadem por dificuldades financeiras. Ampliar também o número de programas e convênios para estágios junto a empresas e escolas, visando facilitar o cumprimento da carga horária obrigatória em estágio curricular supervisionado, para que os alunos tenham suas chances de concluir o curso no tempo previsto aumentadas e também iniciem de maneira tranquila a prática docente.

É de fundamental importância que em cada instituição de ensino superior seja criada uma comissão permanente para estudar periodicamente os fenômenos da evasão nos cursos, classificando-os em fatores internos e externos à instituição e propondo alternativas para combatê-los.

\section{Considerações Finais}

Este artigo apresentou o problema da evasão no Curso de Licenciatura em Informática ofertado no Campus Natal - Zona Norte do IFRN, que entre o período de 2010.1 (período em que se iniciaram as atividades do curso) e o período de 2013.2, atingiu uma taxa de aproximadamente 56\%. Bastante alta, mesmo se tratando de um curso de licenciatura, onde o índice de evasão é significativo [Anibal 2013].

Através da coleta de dados por meio de um website construído exclusivamente para esta pesquisa, os resultados obtidos confirmam que o fenômeno da evasão no referido curso não é um fato independente. Ele conglomera uma série de fatores internos e externos que dificultam nomear qual especificamente deve ser atacado. No entanto, através da pesquisa apresentada neste artigo, foi possível perceber que os principais motivos que levaram os alunos à desistência do curso de Licenciatura em Informática do IFRN foram a dificuldade para conciliar trabalho e estudo, a dificuldade para acompanhar conteúdos de disciplinas específicas, bem como a opção equivocada pelo curso, sendo que este último motivo apresentou um número superior de ocorrências em relação aos demais, indicando neste caso que vários alunos abriram mão do curso em questão logo que tiveram a oportunidade de ingressar em outro com o qual eles tinham maior afinidade ou expectativa.

Evidentemente que parte das causas foge às competências do curso e, portanto, são muito difíceis de combater. Entretanto, cabe refletir um pouco a respeito dos aspectos passíveis de intervenção direta. Neste sentido, sugere-se expandir esta pesquisa, envolvendo os professores para que se obtenha dados de quem enfrenta esses problemas em sua rotina diária e, portanto, ter um conjunto de dados que possibilitem apontar com mais clareza os motivos dos elevados índices de evasão. Além disso, como proposta para um trabalho futuro, dados mais atualizados junto aos que foram apresentados neste artigo podem ser avaliados com mais profundidade, relacionando, por exemplo, as questões socioeconômicas e o interesse pelo curso aos motivos 
considerados decisivos para a evasão dos alunos. O acompanhamento das dificuldades dos alunos que permanecem no curso também pode ser considerado para evitar futuras desistências.

\section{Referências}

Anibal, F. (2013) Evasão em Licenciatura chega a 39\% - Vida e Cidadania - Gazeta do Povo. Disponível em: <http://www.gazetadopovo.com.br/vidaecidadania/conteudo.phtml?id=1392135> Acesso em: 20 de março de 2014.

Brasil. (1996). Ministério da Educação e do Desporto - Comissão Especial de Estudos sobre a Evasão nas Universidades Públicas Brasileiras. Diplomação, retenção e evasão nos cursos de graduação em instituições de ensino superior públicas. Brasília: MEC/SESU.

Bueno, J. L. O. (1993). A Evasão de Alunos. Paidéia, FFCLRP - USP, Ribeirão Preto, n. 5. p. 9-16. In: BRASIL. (1996). Ministério da Educação e do Desporto - Comissão Especial de Estudos sobre a Evasão nas Universidades Públicas Brasileiras. Diplomação, retenção e evasão nos cursos de graduação em instituições de ensino superior públicas. Brasília: MEC/SESU.

Gerhardt, T. E. e Silveira, D. T. (Orgs.). (2009). Métodos de Pesquisa. Porto Alegre: Editora da UFRGS: $1^{\mathrm{a}}$ edição.

Gomes, A. A. (2000). Considerações sobre Evasão Escolar no Ensino Superior. Nuances - Revista Eletrônica do Programa de Pós-Graduação em Educação da Faculdade de Ciências e Tecnologia e do Departamento de Educação, UNESP - Presidente Prudente, São Paulo, v. 6, p. 90-106.

IFRN: Instituto Federal de Educação, Ciência e Tecnologia do Rio Grande do Norte (2012). Projeto Pedagógico do Curso Superior de Licenciatura em Informática. Disponível em <http://portal.ifrn.edu.br/ensino/cursos/cursos-degraduacao/licenciatura/licenciatura-plena-em-informatica/view $>$ Acesso em $21 \mathrm{de}$ março de 2014.

Lobo, M. B. C. M. (2012). Panorama da Evasão no Ensino Superior Brasileiro: Aspectos Gerais das Causas e Soluções. ABMES Cadernos. n. 25. p. 1-23.

Machado, M. R. L. e Moreira, P. R. (2010). Educação profissional no Brasil, evasão escolar e transição para mundo do trabalho. In: Seminário Nacional de Educação Profissional e Tecnológica (SENEPT). Anais do Seminário. Centro Federal de Educação Tecnológica de Minas Gerais (CEFET-MG). Belo Horizonte/MG.

Medeiros, L. M. (2002). Evasão escolar: exclusão ou opção? Rio de Janeiro/RJ, fevereiro. p. 31. Trabalho de Conclusão de Curso (Especialização em Supervisão Escolar) - Universidade Cândido Mendes.

Oliveira, J. F., Catani, A. M., Hey, A. P. e Azevedo, M. L. N. (2014). Democratização do Acesso e Inclusão na Educação Superior No Brasil. Disponível em: $<$ http://flacso.redelivre.org.br/?publication=democratizacao-do-acesso-e-inclusao-naeducacao-superior-no-brasil> Acesso em: 13 de junho de 2014. 
Prietch, S. S. e Pazeto, T. A. (2009). Análise, Sugestões e Perspectivas de um Curso de Licenciatura em Informática. In: XVII Workshop sobre Educação em Computação. Anais do XXIX Congresso da Sociedade Brasileira de Computação. Bento Gonçalves: Editora da SBC, v. 1. p. 557-566.

Ristoff, D. (1995). Evasão: Exclusão ou Mobilidade. Santa Catarina, UFSC. In: BRASIL. (1996). Ministério da Educação e do Desporto - Comissão Especial de Estudos sobre a Evasão nas Universidades Públicas Brasileiras. Diplomação, retenção e evasão nos cursos de graduação em instituições de ensino superior públicas. Brasília: MEC/SESU.

Rocha, M. G. B., Nicoletti, M. C. e Hipólito, O. (2013). Alguns aspectos da formação Graduada em Computação no Brasil. InterSciencePlace - Revista Científica Internacional, v. 1, n. 26, p. 147-169.

Silva, J. A. e Bezerra Junior, E. V. (2014). A Intenção de Evasão Escolar: Discussões e Reflexões no Curso de Licenciatura em Computação do IFTO Campus Porto Nacional. In: $5^{a}$ Jornada de Iniciação Científica e Extensão (JICE) do Instituto Federal do Tocantins. Anais da $5^{a}$ Jornada de Iniciação Científica e Extensão (JICE) do Instituto Federal do Tocantins. Disponível em: $<$ http://propi.ifto.edu.br/ocs/index.php/jice/5jice/schedConf/presentations $>$. Acesso em: Abril de 2014.

Silva Filho, R. L. L., Motejunas, P. R., Hipólito, O. e Lobo, M. B. C. M. (2007). A Evasão no Ensino Superior Brasileiro. Cadernos de Pesquisa - Fundação Carlos Chagas, v. 37, n. 132, p. 641-659.

Souza, O. S. (2014). Um Estudo sobre a Evasão do Curso de Licenciatura em Informática do IFRN / Campus Natal - Zona Norte. Natal/RN, p. 115. Trabalho de Conclusão de Curso de Graduação, Instituto Federal de Educação, Ciência e Tecnologia do Rio Grande do Norte. 